\title{
Novel targeted therapeutics: inhibitors of MDM2, ALK and PARP
}

\author{
Yuan Yuan ${ }^{1}$, Yu-Min Liao², Chung-Tsen Hsueh ${ }^{1}$ and Hamid R Mirshahidi ${ }^{*}$
}

\begin{abstract}
We reviewed preclinical data and clinical development of MDM2 (murine double minute 2), ALK (anaplastic lymphoma kinase) and PARP (poly [ADP-ribose] polymerase) inhibitors. MDM2 binds to p53, and promotes degradation of p53 through ubiquitin-proteasome degradation. JNJ-26854165 and RO5045337 are 2 small-molecule inhibitors of MDM2 in clinical development. ALK is a transmembrane protein and a member of the insulin receptor tyrosine kinases. EML4-ALK fusion gene is identified in approximately 3-13\% of non-small cell lung cancer (NSCLC). Early-phase clinical studies with Crizotinib, an ALK inhibitor, in NSCLC harboring EML4-ALK have demonstrated promising activity with high response rate and prolonged progression-free survival. PARPs are a family of nuclear enzymes that regulates the repair of DNA single-strand breaks through the base excision repair pathway. Randomized phase II study has shown adding PARP-1 inhibitor BSI-201 to cytotoxic chemotherapy improves clinical outcome in patients with triple-negative breast cancer. Olaparib, another oral small-molecule PARP inhibitor, demonstrated encouraging single-agent activity in patients with advanced breast or ovarian cancer. There are 5 other PARP inhibitors currently under active clinical investigation.
\end{abstract}

\section{Introduction}

Modern cancer therapeutics has evolved from non-specific cytotoxic agents that affect both normal and cancer cells to targeted therapies and personalized medicine. Targeted therapies are directed at unique molecular signature of cancer cells to produce greater efficacy with less toxicity. The development and use of such therapeutics allow us to practice personalized medicine and improve cancer care. In this review, we summarized preclinical data and clinical development of three important targeted therapeutics: murine double minute 2 (MDM2), anaplastic lymphoma kinase (ALK) and poly [ADPribose] polymerase (PARP) inhibitors.

\section{Murine Double Minute 2}

MDM2, also known as HDM2 in human, is a negative regulator of tumor suppressor p53 [1]. MDM2 encodes a $90-\mathrm{kDa}$ protein with a p53 binding domain at the Nterminus, and a RING (really interesting gene) domain at the $\mathrm{C}$-terminus functioning as an E3 ligase responsible for p53 ubiquitylation [2]. When wild-type p53 is

\footnotetext{
* Correspondence: hmirshah@llu.edu

'Division of Medical Oncology and Hematology, Loma Linda University Medical Center, Loma Linda, CA 92354, USA

Full list of author information is available at the end of the article
}

activated by various stimuli such as DNA damage, MDM2 binds to p53 at the N-terminus to inhibit the transcriptional activation of $\mathrm{p} 53$, and promote the degradation of $\mathrm{p} 53$ via ubiquitin-proteasome pathway $[3,4]$. MDM2 is overexpressed in a variety of human cancers, including melanoma, non-small cell lung cancer (NSCLC), breast cancer, esophageal cancer, leukemia, non-Hodgkin's lymphoma and sarcoma [5]. MDM2 can interfere with p53-mediated apoptosis and growth arrest of tumor, which is the major oncogenic activity of MDM2 [6,7]. Additionally, MDM2 can cause carcinogenesis independent of p53 pathway [8]. In tumor with homozygous mutant p53, loss of MDM2, which mimics the inhibition of the MDM2p53 interaction, can cause stabilization of mutant p53 and increased incidence of metastasis [9]. Overexpression of MDM2 has been shown to correlate positively with poor prognosis in sarcoma, glioma and acute lymphocytic leukemia [10]. In NSCLC, there have been conflicting results as to whether MDM2 overexpression is associated with worse or better prognosis, but the subset analysis has demonstrated a poor prognostic factor for early-stage NSCLC patients, particularly those with squamous cell histology [11].

\section{Biomed Central}

(c) 2011 Yuan et al; licensee BioMed Central Ltd. This is an Open Access article distributed under the terms of the Creative Commons Attribution License (http://creativecommons.org/licenses/by/2.0), which permits unrestricted use, distribution, and reproduction in any medium, provided the original work is properly cited. 


\section{Preclinical development of MDM2 inhibitors}

Inhibition of MDM2 can restore p53 activity in cancers containing wild-type p53, leading to anti-tumor effects with apoptosis and growth inhibition [12-14]. Animal studies have shown reactivation of p53 function can lead to the suppression of lymphoma, soft tissue sarcoma, and hepatocellular carcinoma [15-17]. Ventura et al. have designed a reactivatable p53 knockout animal model by a a Cre-loxP-based strategy, which a transcription-translation stop cassette flanked by loxP sites (LSL) is inserted in the first intron of the endogenous wildtype p53 locus leading to silencing of p53 expression. Cells from homozygous p53LSL/LSL mice are functionally equivalent to p53 null (p53-/-) cells, and p53LSL/ LSL mice are prone to develop lymphoma and sarcoma. Due to the presence of flanking loxP sites, the stop cassette can be excised by the Cre recombinase, which causes reactivation of p53 expression and regression of autochthonous lymphomas and sarcomas in mice [16].

These results have provided an encouraging direction for p53-target therapeutic strategy utilizing inhibition of MDM2. Since the interaction and functional relationship between MDM2 and p53 have been well characterized, small-molecule inhibitors of MDM2 have been developed by high-throughput screening of chemical libraries [18-20]. As shown in table 1, there are three main categories of MDM2 inhibitors: inhibitors of MDM2-p53 interaction by targeting to MDM2, inhibitor of MDM2p53 interaction by targeting to p53, and inhibitors of MDM2 E3 ubiquitin ligase. The binding sites and mechanism of action for these inhibitors are further illustrated in Figure 1.

Nutlins, consisting of nutlin 1, 2 and 3, analogs of cisimidazoline, fit in the binding pocket of p53 in MDM2

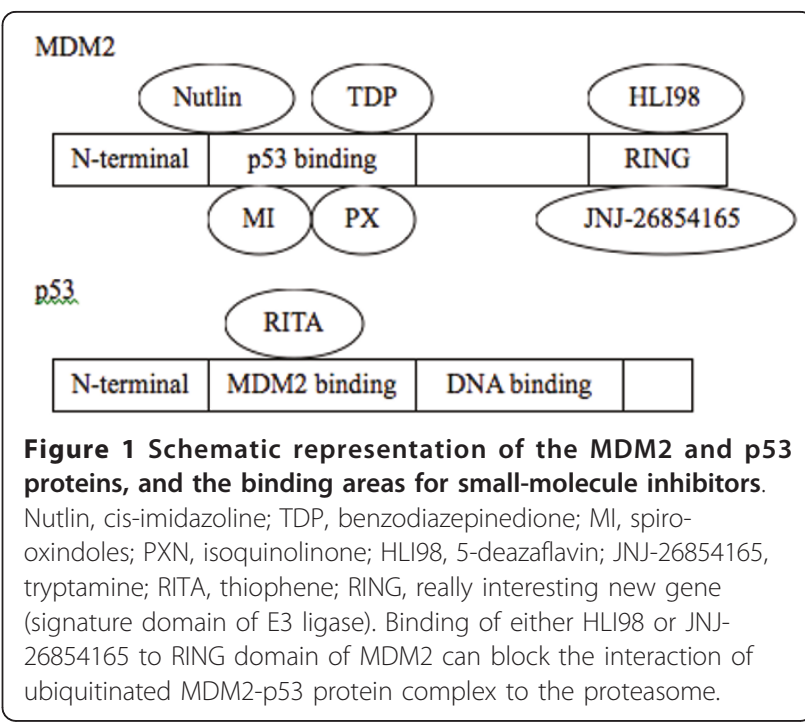

and inhibit the interaction between MDM2 and p53 $[21,22]$. Nutlin-3, an analog of the series, has the most potent binding capacity and lowest inhibition concentration, induced p53 levels, and activated p53 transcriptional activity [23]. Nutlin-3 has been shown to exhibit a broad activity against various cancer models with wildtype p53, such as breast, colon, neuroblastoma, mantle cell lymphoma and osteosarcoma [24-27]. Nutlin-3 activates p53 and induces apoptosis and cellular senescence in myeloid and lymphoid leukemic cells \{Hasegawa, $2009 \# 149\}$. In the absence of functional p53, nutlin-3 interrupts the interaction between p73 and MDM2, and increases p73 transcriptional activity, leading to enhanced apoptosis and growth inhibition of leukemic cell [30].

Table 1 MDM2 inhibitors in development

\begin{tabular}{ccc}
\hline Chemical series & Therapeutics & Development stage \\
\hline Cis-imidazoline & Inhibitors of MDM2-p53 interaction by targeting to MDM2 & Phase I: \\
& RO5045337 (RG7112; Nutlin-3) & Advanced solid tumors and hematological malignancy \\
\hline Benzodiazepinedione & TDP521252 \& TDP665759 & Preclinical \\
\hline Spiro-oxindoles & MI-219, & Preclinical \\
\hline Ml-319 \& other Ml compounds & Preclinical \\
\hline PXN727 \& PXN822 & Preclinical \\
\hline Inhibitor of MDM2-p53 interaction by targeting to p53 & \\
\hline RITA & Preclinical \\
\hline 5-Deazaflavin & E3 Ligase Inhibitors & Phase I: \\
\hline Tryptamine & HLI98 compounds & Advanced solid tumors \\
\hline
\end{tabular}

RITA, reactivation of $p 53$ and induction of tumor cell apoptosis.

Reference; [23,36,37,130-132,134-139]. 
MDM4 (also known as MDMX), an MDM2 homolog, binds p53 and inhibits p53 activity without causing degradation of p53 degradation [31]. Furthermore, despite the similarity between MDM2 and MDM4, MDM2 inhibitors such as nutlin-3 are far less effective against MDM4 [32]. Small-molecule inhibitor of MDM4 has been developed through a reporter-based drug screening [33]. MDM4 inhibitor not only can activate p53 and induce apoptosis in breast cancer MCF-7 cells, but can also synergize with MDM2 inhibitor for p53 activation and induction of apoptosis.

\section{Clinical development of MDM2 inhibitors}

JNJ-26854165, a novel tryptamine derivative, is an oral MDM2 inhibitor. Pre-clinical studies have shown binding of JNJ-26854165 to RING domain of MDM2 inhibits the interaction of MDM2-p53 complex to the proteasome, and increases p53 level [19]. Furthermore, induction of apoptosis and anti-proliferation independent of p53 in various tumor models including breast cancer, multiple myeloma and leukemia were shown [34-36]. The presence of p53-independent apoptotic activity in addition to p53-mediated apoptosis is regarded as an advantage to prevent the selection of p53 mutant subclones in cancer during treatment of JNJ-26854165. Results for phase I study (clinicaltrial.gov identifier: NCT00676910) using continuously daily oral dosing in patients with advanced solid tumors were presented in 2009 annual meeting of American Society of Clinical Oncology (ASCO) [37]. Forty-seven patients were treated at 11 dose levels, ranging from 4 to $400 \mathrm{mg}$ daily. Treatment was well tolerated with frequent adverse events in grade 1-2: nausea, vomiting, fatigue, anorexia, insomnia, electrolyte imbalance, and mild renal/liver function impairment. No hematological or cardiovascular toxicities were observed. One patient at $300 \mathrm{mg}$ dose level experienced dose-limiting toxicity (DLT) with grade 3 asymptomatic QTc prolongation, which resolved after discontinuation of treatment. Dose escalation was stopped at $400 \mathrm{mg}$ dose level due to 2 out of 3 patients had DLT including one grade 3 skin rash and one grade 3 QTc prolongation. There was no objective response, but 3 patients with prolonged SD including one breast cancer overexpressing human epidermal growth factor receptor 2. Pharmacokinetic study demonstrated linear pharmacokinetics in 20 to $400 \mathrm{mg}$ dose range, with preclinical determined therapeutic concentration achieved at dose level of $300 \mathrm{mg}$ and above. Pharmacodynamic study showed upregulation of p53 in skin, increase of HDM2 levels in tumors, and increase of plasma macrophage inhibitory cytokine-1 (MIC-1) levels in dosedependent manner. MIC-1, a transforming growth factor-B superfamily cytokine, is induced by $\mathrm{p} 53$ activation, and secreted MIC-1 levels can serve as a biomarker for p53 activation [38]. Dose level of $350 \mathrm{mg}$ was used on expanded cohort of patients to confirm maximum tolerated dose, and trial with alternate dosing schedule to minimize QTc prolongation was started with $150 \mathrm{mg}$ twice a day.

RO5045337 (RG7112), an oral formulation of nutlin-3, is currently in phase I studies for patients with advanced solid tumors (NCT00559533), and refractory acute leukemias and chronic lymphocytic leukemia (NCT00623870). Both studies are to determine the maximum tolerated dose and the optimal dosing schedule of RO5045337, administered as monotherapy. Preliminary data has shown acceptable safety profiles with responses seen in patients with liposarcoma, acute myelogenous leukemia and chronic lymphocytic leukemia.

\section{Anaplastic Lymphoma Kinase}

ALK is a 1620 amino acid transmembrane protein, consisting of extracellular domain with amino-terminal signal peptide, intracellular domain with a juxtamembranous segment harboring a binding site for insulin receptor substrate-1, and a carboxy-terminal kinase domain [39]. ALK is a member of the insulin receptor tyrosine kinases, and the physiological function of ALK remains unclear [40]. Translocation of ALK occurs in about $50 \%$ of anaplastic large-cell lymphoma (ALCL), and $80 \%$ of them have the $t(2 ; 5)$ chromosomal translocation with NPM-ALK expression [41]. The $t$ (2; 5) translocation generates a fusion protein with carboxyterminal kinase domain of ALK on chromosome 2, and the amino-terminal portion of nucleophosmin (NPM) on chromosome 5. NPM is the most common fusion partner of ALK, but at least six other fusion partners have been identified. In these fusion proteins, the amino-terminal portion is responsible for protein oligomerization, which activates ALK kinase and downstream signaling such as Akt, STAT3, and extracellular signalregulated kinase 1 and 2 [42] (Figure 2).

Mutations of ALK have been identified in $6-12 \%$ of sporadic neuroblastoma, and preclinical studies have demonstrated these mutations promote ALK kinase activity leading to oncogenic events [43]. It has been postulated that activation of ALK provides oncogenic addiction to tumors harboring activating mutation or translocation of ALK [44]. Knock-down of ALK by small hairpin RNA targeting ALK in NPM-ALK-containing tumor models gives raise to growth inhibition and apoptosis [45]. This indicates inhibition of ALK may be an effective therapeutic strategy for tumors harboring ALK activation.

Echinoderm microtubule-associated protein-like 4 (EML4) is a $120 \mathrm{KDa}$ cytoplasmic protein, which involves in the formation of microtubules and microtubule binding protein [46]. EML4-ALK is a novel fusion 


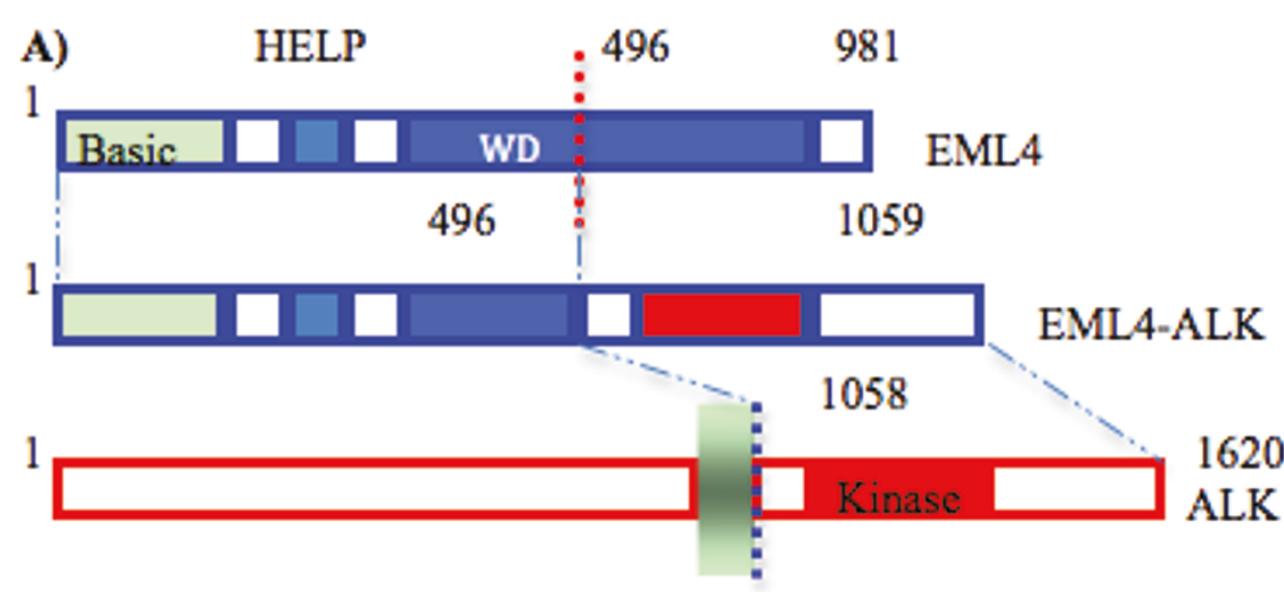

TM

B)

ALK

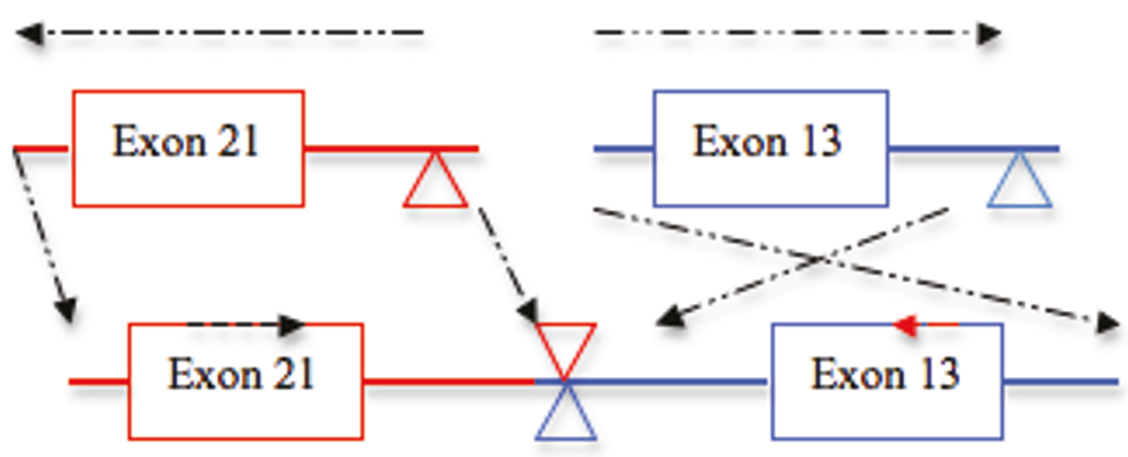

EML4-ALK.

Figure 2 Schematic representation of the EML-4 and ALK translocation. A) Fusion of the N-terminal portion of EML4 (comprising the basic region, the HELP domain and part of the WD-repeat region) to the intracellular region of ALK (including the tyrosine kinase domain). TM, transmembrane domain. B) Both the ALK gene and the EML4 gene plot to chromosome 2p, but have opposite orientations. In the NSCLC EML4 is interrupted at a position $3.6 \mathrm{~kb}$ downstream of exon 13 and is attached to a position 297 bp upstream of exon 21 of ALK, creating the EML4ALK (variant 1) fusion gene.

gene arising from an inversion on the short arm of chromosome 2 [Inv (2)(p21p23)] that joined exons 1-13 of EML4 to exons 20-29 of ALK $[47,48]$. Soda et al. identified this fusion gene as a transforming activity in mouse 3T3 fibroblasts from DNA of lung cancer in a Japanese man with a smoking history in 2007 [48]. EML4-ALK fusion protein consists of the complete tyrosine kinase domain of ALK at and the carboxy-terminal, and promoter of the $5^{\prime}$ partner gene controls the transcription of the resulting fusion gene. Multiple variants of EML4-ALK have been identified, and all the variants encode the same cytoplasmic portion of ALK but different truncations of EML4 (at exons 2, 6, 13, 14, 15, 18, and 20). In lung cancer the chimeric protein involves ALK fused most commonly but not exclusively to EML4. Other rare fusion partners are TRK-fused gene 11 (TFG 11) and KIF5B (Kinesin heavy chain) [47-51]. ALK gene rearrangements and the resulting fusion proteins in tumor specimen can be identified by fluorescent in situ hybridization (FISH), immunohistochemistry (IHC), and reverse transcription-polymerase chain reaction (RT-PCR).

The presence of EML4-ALK fusion is identified in approximately $3-13 \%$ of NSCLC, and mutually exclusive with the presence of epidermal growth factor receptor (EGFR) mutation [48,52-55]. EML4-ALK fusion 
transcript is not identified in other cancer types such as gastrointestinal and breast cancers [56]. Shaw et al. investigated the clinical features of NSCLC patients harboring EML4-ALK fusion rearrangement [55]. Among 141 patients, they found 19 (13\%) patients carried the EML4-ALK rearrangement, 31 (22\%) harbored an activating EGFR mutation, and 91 (65\%) were wild type for both ALK and EGFR (designated WT/WT). EML4ALK-positive patients were significantly younger than patients with either EGFR mutation or WT/WT $(\mathrm{P}<$ 0.001 and $\mathrm{P}=0.005$, respectively). EML4-ALK-positive patients were more likely to be men than patients with either EGFR mutation or WT/WT $(\mathrm{P}=0.036$ and $\mathrm{P}=$ 0.039, respectively). EML4-ALK-positive patients were significantly never or light smokers compared with the WT/WT patients $(\mathrm{P}<0.001)$, and did not benefit from treatment with EGFR tyrosine kinase inhibitors (TKIs). Eighteen EML4-ALK-positive patients had adenocarcinoma and one patient had mixed adenosquamous histology. However, patients with EML4-ALK-positive NSCLC did not have exclusively adenocarcinoma histology in two other studies $[51,53]$.

Focusing on the clinical outcome, Shaw et al. examined 477 NSCLC patients, and identified 43 patients (9\%) with EML4-ALK rearrangements, 99 patients (21\%) with EGFR mutations, and 335 patients (70\%) with WT/ WT [57]. EML4-ALK-positive patients were significantly younger (median age 54 vs 64 years old, $\mathrm{p}<0.001$ ) and more likely to be never or light smokers (90\% vs $37 \%$, p $<0.001)$, compared with WT/WT patients. There was no difference in overall survival (OS) between patients with EML4-ALK fusion and EGFR mutation (1-year OS: $82 \%$ vs $81 \%, \mathrm{p}=0.79$ ); however, both groups demonstrated a longer OS than WT/WT patients (1-year OS $66 \%, \mathrm{p}<0.001)$. This data suggests the better outcome in patients with EML4-ALK rearrangement vs. patients with WT/WT may be related to differences in biology, demographic features, and availability of targeted therapies.

\section{Preclinical development of ALK inhibitors}

The development of ALK small-molecule inhibitors has been hampered due to lack of ALK protein structure. Initial testing and development of ALK inhibitors were done with naturally occurring sources such as staurosporine and HSP90 inhibitors, which are not potent and specific inhibitors of ALK [58]. Subsequently, using homology modeling to assist the screening and synthesis, more potent and specific ALK inhibitors have been developed [59]. Although there are multiple partners for the ALK translocation, all the fusion proteins contain the ALK kinase domain and should be susceptible to ALK kinase inhibition. As shown in table 2, there are at least 9 different chemical classes of small-molecule inhibitors of ALK being developed.

PF-2341066 (Crizotinib), derivative of aminopyridine, was initially developed as a potent, orally bioavailable, ATP-competitive small-molecule inhibitor of c-MET and hepatocyte growth factor receptor [60]. Further investigation has indicated Crizotinib is a potent inhibitor of ALK as well, and half maximal inhibitory concentration $\left(\mathrm{IC}_{50}\right)$ for either $\mathrm{c}-\mathrm{MET}$ or ALK overexpressing cell line is $\sim 20 \mathrm{nM}$. Crizotinib suppresses the proliferation of ALCL cell line with ALK activation, but not in ALCL cell lines without ALK activation. Crizotinib inhibits phosphorylation of ALK, and causes complete regression of ALCL harboring NPM-ALK fusion in xenograft model [61]. Crizotinib also inhibits the proliferation in NSCLC (such as H3122) and neuroblastoma cell lines harboring ALK activation [62]. Experiments

Table 2 ALK inhibitors in development

\begin{tabular}{ccc}
\hline Chemical series & Therapeutics & Development stage \\
\hline Aminopyridine & PF-2341066 (crizotinib) & Phase II/II: NSCLC; phase I/II: advanced solid tumors, neuroblastoma, and ALCL \\
\hline Diaminopyrimidine & CEP-28122 & $\begin{array}{c}\text { Preclinical } \\
\text { IND application expected }\end{array}$ \\
\hline Structure undisclosed & AP-26113 & Preclinical \\
\hline Structure undisclosed & X-276 & IND application expected in 2011 \\
\hline Pyridoisoquinoline & F91873 and F91874 & Preclinical \\
\hline Pyrrolopyrazole & PHA-E429 & Preclinical \\
\hline Indolocarbazole & CEP-14083 and CEP-14513 & Preclinical \\
\hline Pyrrolopyrimidine & GSK1838705A & Preclinical \\
& & No further development \\
\hline Dianilinopyrimidine & NVP-TAE684 & Preclinical \\
& & No further development \\
\hline
\end{tabular}

NSCLC, non-small cell lung cancer; ALCL, anaplastic large cell lymphoma

Reference $[60,61,64,65,140-150]$ 
using NCI-H441 NSCLC xenografts showed a $43 \%$ decrease in mean tumor volume, with 3 of 11 mice exhibiting a $>30 \%$ decrease in tumor mass and 3 animals with no evidence of tumor at the end of the 38-day crizotinib treatment [60]. Crizotinib is currently undergoing active clinical investigation in NSCLC. Additionally, phase I/II study is conducted in patients with advanced malignancy such as ALCL or neuroblastoma (NCT00939770).

Second-generation ALK inhibitors such as AP-26113 and X-276 are considered more potent and selective inhibitors of ALK than crizotinib. AP-26113, an orally bioavailable inhibitor of ALK with undisclosed structure, is developed by Ariad [63]. During preclinical investigation, AP-26113 has been shown to inhibit not only the wild-type ALK but also mutant forms of ALK, which are resistant to the first-generation ALK inhibitor such as crizotinib. Further studies have demonstrated AP26113 is at least 10 -fold more potent and selective in ALK inhibition than crizotinib $[64,65]$.

\section{Clinical development of ALK inhibitors}

In 2009 annual meeting of ASCO, Kwat et al. reported the results of phase I dose escalation study and expanded phase II study of crizotinib [66]. Thirty-seven patients with advanced solid tumors including 3 NSCLC patients were enrolled in phase I study. The maximum tolerated dose of crizotinib was $250 \mathrm{mg}$ orally twice a day, and 2 fatigue DLT were noted in the next dose level at $300 \mathrm{mg}$ twice a day. The major side effects were fatigue, nausea, vomiting and diarrhea; but were manageable and reversible. There was 1 partial response $(\mathrm{PR})$ in a sarcoma patient with ALK rearrangement. Additionally, a dramatic clinical response was observed in a NSCLC patient harboring EML4-ALK rearrangement. Therefore, an expanded phase II study using 250 mg of crizotinib twice a day was conducted in 27 NSCLC patients harboring EML4-ALK tumor determined by FISH. In the first 19 evaluable patients, there were 17 patients with adenocarcinoma (90\%) and 14 non-smokers (74\%). Overall response rate (RR) was 53\%, and disease control rate (DCR; complete response [CR]/ $\mathrm{PR} /$ stable disease [SD]) was $79 \%$ at 8 weeks. Only 4 patients $(21 \%)$ progressed after 8 weeks of treatment, despite more than $60 \%$ of patients received 2 or more lines of treatment prior to entering this study.

Bang et al. presented the follow up results on the expanded phase II study of crizotinib in NSCLC patients with EML4-ALK rearrangement in 2010 annual meeting of ASCO [67]. Eighty-two patients were evaluable, with 96\% adenocarcinoma, 76\% never-smokers and $~ 95 \%$ having prior treatment. Overall RR was $57 \%$, with estimated 6-month progression-free survival (PFS) rate of $72 \%$, and DCR of $87 \%$ at 8 weeks. The median progression-free survival was not yet mature, and the median duration of treatment was 25.5 weeks. Radiological responses typically were observed at the first or second restaging CT scan. Main side effects were nausea, diarrhea and visual disturbance on light/dark accommodation without abnormality on eye examination. The results of this phase II study have been recently published [68].

Based on these encouraging results, a randomized phase III trial comparing crizotinib to standard secondline cytotoxic chemotherapy docetaxel and pemetrexed in patients with ALK-positive NSCLC has now commenced (NCT00932893). The combination of erlotinib and crizotinib is also being tested in patients who failed prior chemotherapies regardless of EML4/ALK translocation status (NCT00965731). A phase III study to evaluate crizotinib as first line therapy in EML4-ALK translocation patients compare to standard platinum based chemotherapy is underway (NCT01154140).

\section{Poly ADP-Ribose Polymerases}

PARPs are a family of nuclear enzymes that regulates the repair of DNA single-strand breaks (SSBs) through the base-excision repair (BER) pathway [69]. Upon DNA damage, PARP cleaves nicotinamide adenine dinucleotide $\left(\mathrm{NAD}^{+}\right)$to generate poly (ADP-ribose) (PAR) polymers, which are added onto DNA, histones, DNA repair proteins and PARP [70,71]. These hetero- and automodification processes mediated by PARP lead to recruitment of repair machinery to facilitate BER process. Among the 17 members of PARP, PARP-1 and PARP-2 are the only members known to be activated by DNA damage and may compensate for each other [72]. PARP-1 is best characterized and responsible for most if not all the DNA-damage-dependent PAR synthesis; exhibits with $\mathrm{N}$-terminal DNA-binding domain, central auto-modification domain, and C-terminal catalytic domain, which is the "signature" for PARP family. Although lacks of central auto-modification domain, PARP-2 shares $\sim 70 \%$ homology of catalytic domain as PARP-1, and provides residual PARP activity $(\sim 15 \%)$ in the absence of PARP-1 [73]. The physiological functions of PARP-1 and PARP-2 have been further explored in knockout models [74]. Double PARP-1 and PARP-2 knockout mice are lethal at the embryonic stage. Knockout of either PARP-1 or PARP-2 results in increased genomic instability by accumulation of DNA SSBs, and causes hypersensitivity to ionizing radiation and alkylating agents. Additionally, PARP-1 also plays important roles in cellular responses to ischemia, inflammation and necrosis.

Targeting the PARP-mediated DNA repair pathway is a promising therapeutic approach for potentiating the effects of chemotherapy and radiation therapy and 
overcoming drug resistance [75]. However, the most exciting use of PARP inhibitors may be utilizing a phenomenon called synthetic lethality [76]. Synthetic lethality is a cellular condition in which simultaneous loss of two nonessential mutations results in cell death, which dose not occur if either gene products is present and functional [77]. Tumors with DNA repair defects, such as those arising from patients with BRCA mutations were found to be more sensitive to PARP inhibition due to synthetic lethality. The BRCA1 and BRCA2 gene encodes large proteins that coordinate the homologous recombination repair double strand breaks (DSBs) pathway [78]. Since BRCA1/2-mutated tumors cannot utilize homologous recombination to repair DSBs, exposing these cells to PARP inhibitor, which shuts down BER rescue pathway, will lead to accumulation of DNA damage, genomic instability and cell death (Figure 3).

A.

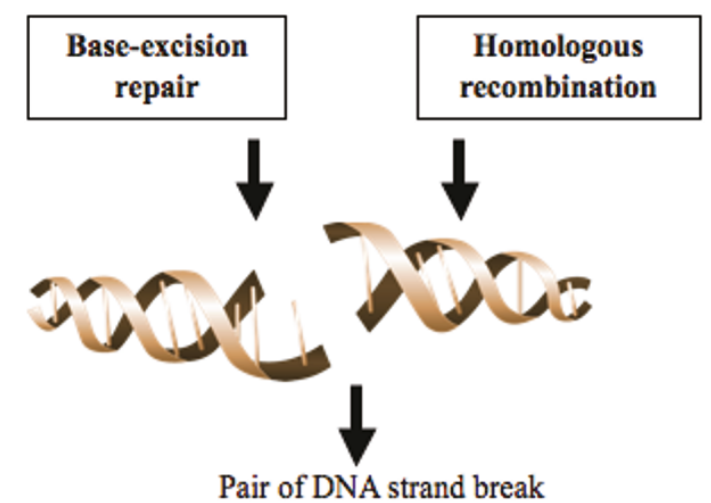

B.

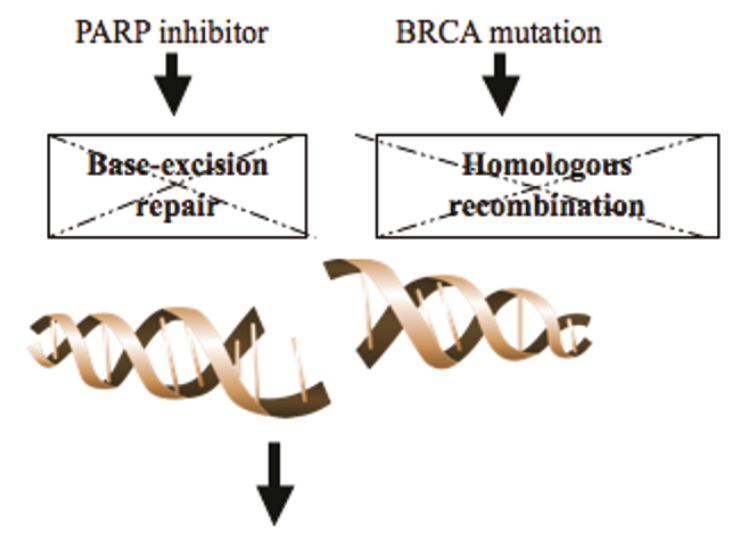

No repair of DNA strand breaks Cell death

Figure 3 Schematic representation of PARP and BRCA mediated DNA repair in cells without exposure to PARP inhibitor and BRCA mutation (A), and synthetic lethality in cells with BRCA mutation exposing to PARP inhibitor (B).

\section{Preclinical development of PARP inhibitors}

Inhibition of PARP has been developed in the laboratory for more than 30 years, with analogues mimicking nicotinamide component of $\mathrm{NAD}^{+}$for binding to catalytic site of PARP [70,79]. Preclinical data reporting efficacy of PARP inhibitors in a $B R C A$ mutated population was initially reported in 2005 [80,81]. Bryant et al. revealed that low concentrations of PARP inhibitors produced cytotoxicity on BRCA2-deficient cell lines with defects in homologous recombination, but not in cell lines with intact homologous recombination. When BRCA2 function was restored in these cell lines, the cells were no longer subject to inhibition of PARP. In other breast cancer cell lines such as MCF-7 and MDA-MB-231, similar sensitivity to PARP inhibition was observed when BRCA2 was depleted. Similarly, Farmer et al. demonstrated that PARP inhibitors NU1025 and AG14361 were highly cytotoxic in BRCA2-deficient VC-8 cells [80]. Additionally, cell death increased when BRCA1/2 deficient cells were transfected with small interfering RNA targeting PARP-1. Enhanced sensitivity to PARP inhibition in BRCA-deficient cells was observed when DNAdamaging agents were added in vitro. These preclinical data serve as proof-of-concept for synthetic lethality in BRCA-deficient cell lines and provide important rationale for studying PARP inhibitors in patients with BRCA1/2asssociated breast and ovarian cancer.

Further investigations have identified triple-negative breast cancer (TNBC, breast cancer without over-expression of estrogen, progesterone and HER2-neu receptors, accounts for about 15 percent of all breast cancers) and sporadic serous ovarian cancer without mutations of BRCA1/2 but exhibit properties of BRCA1- or BRCA2deficient cells, known as "BRCAness" [82]. BRCAness cancers have defects in homologous recombination due to dysfunctional BRCA1/2 from epigenetic modification, and/or deficiency in proteins involved in homologous recombination repair pathways, such as RAD51, RAD54, DSS1, RPA1, ATM, CHK2 and PTEN [83-85]. Preclinical studies have shown BRCAness cancer cells are more sensitive to PARP inhibition especially in the presence of DNA-damaging agents such as cisplatin, vs. non-BRCAness [86]. These important findings have further expanded the therapeutic application of PARP inhibitors in cancers with acquired defect in homologous recombination other than germline BRCA mutations.

As shown in table 3, there are currently 9 different PARP inhibitors at different stages of clinical development, and at least 3 highly selective PARP inhibitors in preclinical development. Because both PARP-1 and PARP-2 share high degree of homology in catalytic domain, most of the PARP inhibitors under clinical development do not have significant differential activity against either PARP-1 or PARP-2 [69]. Using $x$-ray crystal structure and homology 
Table 3 PARP inhibitors in development

\begin{tabular}{|c|c|c|}
\hline $\begin{array}{l}\text { Chemical } \\
\text { series }\end{array}$ & Therapeutics & Development stage \\
\hline Benzamide & $\begin{array}{l}\text { BSI-201 } \\
\text { (iniparib) }\end{array}$ & 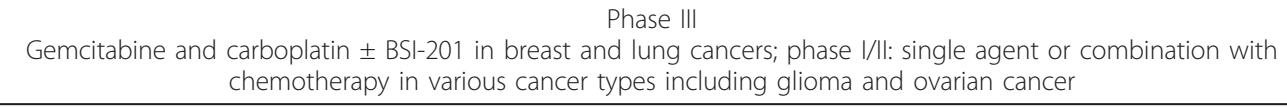 \\
\hline Phthalazinone & $\begin{array}{l}\text { AZD2281 } \\
\text { (olaparib) }\end{array}$ & $\begin{array}{c}\text { Phase } 1 / \| \\
\text { Single agent or combination with chemotherapy in various cancer types including breast, ovarian and colorectal } \\
\text { cancers }\end{array}$ \\
\hline Tricyclic indole & $\begin{array}{l}\text { AG-014699 } \\
\text { (PF-01367338) }\end{array}$ & $\begin{array}{c}\text { Phase II } \\
\text { Single agent in BRCA-associated breast or ovarian cancer; Phase I: combination with chemotherapy in advanced } \\
\text { solid tumors }\end{array}$ \\
\hline Benzimidazole & $\begin{array}{l}\text { ABT-888 } \\
\text { (Veliparib) }\end{array}$ & $\begin{array}{c}\text { Phase } \| \\
\begin{array}{c}\text { Combination with chemotherapy in various cancer types including breast cancer, colorectal cancer, glioblastoma } \\
\text { multiforme and melanoma; phase I: combination with radiation }\end{array}\end{array}$ \\
\hline Indazole & MK-4827 & $\begin{array}{l}\text { Phase I } \\
\text { Single agent; combination with carboplatin-containing regimens }\end{array}$ \\
\hline Pyrrolocarbazole & CEP-9722 & $\begin{array}{c}\text { Phase I } \\
\text { Combination with temozolomide in advanced solid tumors }\end{array}$ \\
\hline Phthalazinone & $\begin{array}{c}E 7016 \\
(\mathrm{GPl}-21016)\end{array}$ & $\begin{array}{c}\text { Phase I } \\
\text { Combination with temozolomide in advanced solid tumors }\end{array}$ \\
\hline Isoindolinone & INO-1001 & $\begin{array}{c}\text { Phase I } \\
\text { Combination with temozolomide in melanoma (completed) without further investigation in oncology; phase II in } \\
\text { cardiovascular disease }\end{array}$ \\
\hline $\begin{array}{l}\text { Structure } \\
\text { undisclosed }\end{array}$ & MP-124 & Phase I in acute ischemic stroke \\
\hline $\begin{array}{l}\text { Structure } \\
\text { undisclosed }\end{array}$ & LT-00673 & Preclinical \\
\hline $\begin{array}{c}\text { Structure } \\
\text { undisclosed }\end{array}$ & NMS-P118 & Preclinical \\
\hline $\begin{array}{l}\text { Structure } \\
\text { undisclosed }\end{array}$ & XAV939 & Preclinical, highly selective against PARP-5 (tankyrase) \\
\hline
\end{tabular}

modeling, highly selective inhibitors against either PARP-1 or PARP-2 have been successfully developed [87-89]. Over-activation of PARP-1 due to DNA damage from ischemic event is responsible for post-ischemic cell death in neurons and myocardial cells, and PARP-1 knockout mice are more resistant to the damage from ischemic insults [90,91]. PARP inhibitors such as INO-1001 and MP-124 have been studied in animal models and clinical settings as neuroprotectant and cardiac protectant during ischemic insults [92-94].

PARP-5a and PARP-5b, also known as tankyrase 1 and tankyrase 2 , are involved in telomere metabolism and Wnt/ $\beta$-catenin signaling [69]. Moreover, tankyrase inhibition imposes selective lethality on BRCA deficient cell lines [95]. XAV939, a small molecule which suppresses $\beta$-catenin-mediated transcription by stabiling axin and degrading $\beta$-catenin, is found to inhibit tankyrases [96]. Molecule like XAV939 can be used to target cancers harboring BRCA (such as breast cancer) and/or dysregulated Wnt- $\beta$-catenin signaling (such as colorectal cancer) without affecting PARP-1.

\section{Clinical development of PARP inhibitors}

Seven PARP inhibitors are currently in clinical development in oncology. Most of phase I studies have used pharmacodynamic analysis of PARP-1 activity in peripheral blood mononuclear cells (PBMCs) to determine the optimal PARP inhibitory dose. There are 2 main investigational approaches: single-agent study in BRCA-associated and BRCAness cancers; combination study with DNA-damage agent and/or radiation. BSI201 (Sanofi-Aventis) is currently in a phase III trial for TNBC in combination with gemcitabine and carboplatin. AZD2281 (Astra-Zeneca), AG-014966 (Pfizer) and ABT-888 (Abott), are in phase II clinical trials as single agent or in combination with chemotherapy. MK4827 (Merck), CEP-9722 (Cephalon) and E7016 (Eisai) are in phase I clinical trials. INO-1001 (Inotek) is no longer in clinical development after completion of a phase IB study in combination with temozolomide in patients with advanced melanoma [97], and there is no updated information available on this compound $[98,99]$. 


\section{BSI-201 (Iniparib)}

BSI-201 is different from other PARP inhibitors, due to drug discovery from interacting with DNA binding domain of PARP-1 instead of catalytic site of PARP [100]. By disrupting the binding between PARP-1 and DNA, BSI-201, a noncompetitive PARP-1 inhibitor, attenuates PARP-1 activation. Phase I study of BSI-201 in advanced solid tumors has demonstrated good tolerability without an identified MTD with dose levels ranging from $0.5 \mathrm{mg} / \mathrm{kg}$ to $8.0 \mathrm{mg} / \mathrm{kg}$ IV twice weekly. The most common adverse event was gastrointestinal toxicity (39\%). At dose level of $2.8 \mathrm{mg} / \mathrm{kg}$, PARP was inhibited in PBMCs by greater than $50 \%$ after a single dose, with greater inhibition observed ( $80 \%$ or more) after multiple dosing [101]. A phase IB study combining BSI-201 with various chemotherapeutic agents such topotecan, gemcitabine, temozolomide, and carboplatin/paclitaxel in patients with advanced solid tumors has shown acceptable safety profiles at doses levels ranging from 1.1 to 8.0 $\mathrm{mg} / \mathrm{kg}$ iv twice a week [102]. Significant PARP inhibition was again noted at dose levels of $2.8 \mathrm{mg} / \mathrm{kg}$ or higher. Of 55 patients in this study, there were one CR (ovarian cancer), 5 PR (2 breast cancer, and 3 other cancer types) and 19 SD. In 2009, O'Shaughnessy et al. presented the results of a randomized phase II study comparing gemcitabine plus carboplatin with or without BSI-201 $(5.6 \mathrm{mg} /$ kg; iv; biweekly $n$ days $1,4,8$, and 11 every 21 days) in patients with TNBC [103]. The addition of BSI-201 improved RR from $16 \%$ to $48 \%(\mathrm{p}=0.002)$, and DCR from $21 \%$ to $62 \%$. Median PFS was improved from 3.3 to 6.9 months (hazard ratio [HR] 0.34, p < 0.001). Final result of this phase II study was reported at 2009 San Antonio Breast Cancer Symposium with overall survival was improved from 7.7 to 12.2 month (HR 0.5, p = 0.005) [104]. It's noted that no significant difference in myelotoxicity was seen between the two treatment arms. An updated analysis reported at 2010 European Society for Medical Oncology meeting showed PFS was improved from 3.6 months to 5.9 months (HR 0.59) and DCR was improved from $33.9 \%$ to $55.7 \%$ ( $p=0.015)$, median overall survival benefit remain similar (7.7 months vs. 12.3 months, HR 0.57). A randomized phase III study comparing gemcitabine plus carboplatin with or without BSI-201 in patients with TNBC is currently underway (NCT00938652). Similar treatment design is used for an ongoing phase III study in patients with stage IV squamous cell lung cancer (NCT01082549). BSI-201 is also currently being evaluated as single agent or combination with chemotherapy in phase I/II studies in various cancer types including glioma and ovarian cancer.

\section{AZD2281 (Olaparib)}

Fong et al. reported the results of phase I study of olaparib, which is an oral small-molecule PARP inhibitor
$[105,106]$. The frequently occurred toxicities were nausea, vomiting, diarrhea, and fatigue. Maximum tolerated dose (MTD) was identified at $400 \mathrm{mg}$ twice daily, with grade 3 fatigue and mood alteration DLT noted in one of eight patients at this dose level. Grade 4 thrombocytopenia and grade 3 somnolence occurred in two of five patients receiving $600 \mathrm{mg}$ twice daily. In a group of 19 patients with breast, ovarian or prostate caners with known BRCA mutation, RR of $47 \%$ and DCR of $63 \%$ were observed without profound difference in toxicity profiles in comparison with non-BRCA mutated patients [106]. The subsequent phase II study in 27 breast cancer patients with BRCA mutation (18 BRCA1 deficient and 9 BRCA2 deficient) showed RR of $41 \%$ and median PFS of 5.7 months [107]. The pooled analysis of 50 ovarian cancer patients with BRCA1/2-mutation treated on phase I and II studies (11 on phase I, and 39 on phase phase II receiving olaparib $200 \mathrm{mg}$ twice daily) showed RR of $40 \%$ and DCR of $46 \%$, predominately in platinumsensitive group [108].

Two subsequent Phase II studies evaluating olaparib in previously treated BRCA1/2-mutated breast cancer and ovarian cancer patients were recently reported $[104,109,110]$. In both studies, patients were treated with either $100 \mathrm{mg}$ or $400 \mathrm{mg}$ of olaparib twice daily. Fifty-seven ovarian cancer patients and 54 breast cancer patients were studies respectively. Overall RR in the ovarian cancer study was $33 \%$ in the high-dose group and $13 \%$ in the low-dose group. Overall RR in the breast cancer study was $41 \%$ in the high-dose group and $22 \%$ in the low-dose group.

Interestingly, reported in 2010 annual meeting of ASCO, a provocative phase II study of olaparib showed promising results for women with high-grade serous ovarian cancer regardless of BRCA mutation status [111]. Patients with advanced breast or ovarian cancer were treated with single agent olaparib $400 \mathrm{mg}$ twice daily continuously for 28 -day cycle. Of 64 women with ovarian cancer in the study, the overall RR was $41.2 \%$ and $23.9 \%$, respectively, for patients with and without BRCA mutations. However, no response was seen in the 24 patients with TNBC treated with olaparib. This is the first single-agent trial demonstrating promising activity of olaparib in high-grade non-BRCA mutated sporadic serous ovarian caner. The mechanism could be attributed by underlying DNA repair abnormalities, which may lead to "BRCAness"[82,112].

Combinations of olaparib and chemotherapy agents have been explored. Myelosuppresion decreases tolerability when combine olaparib with chemotherapy agents [113]. Dent et al. reported a phase I/II study of olaparib in combination with weekly paclitaxel as first or second-line treatment in patients with metastatic TNBC [114]. Olaparib $200 \mathrm{mg}$ twice daily was given 
continuously with paclitaxel $90 \mathrm{mg} / \mathrm{m}^{2}$ weekly for 3 of 4 weeks. Toxicity included 58\% neutropenia, $63 \%$ diarrhea, $58 \%$ nausea, and $53 \%$ fatigue, and most were grade 1-2 except neutropenia. Of 19 patients treated in two cohorts, RR of 33 to $40 \%$ and median PFS of 5.2 to 6.3 months were observed.

\section{AG-014699 (PF-01367338)}

AG-014699, an intravenous PARP inhibitor, was studied in combination with temozolomide in advanced solid tumors [115]. PARP inhibitory dose was decided at $12 \mathrm{mg} / \mathrm{m}^{2}$ IV daily for 5 days every 4 weeks based on $74 \%$ to $97 \%$ inhibition of peripheral blood lymphocyte PARP activity. Mean tumor PARP inhibition at 5 h was $92 \%$ (range, 46-97\%). No significant toxicity was seen from AG-014699 alone, and AG-014699 showed linear pharmacokinetics without interaction with temozolomide. A phase II study with this combination as $1^{\text {st }}$ line treatment of 40 patients with metastatic melanoma showed RR of $10 \%$ and SD of $10 \%$, with significant bone marrow suppression being the major toxicity [116]. Currently, this compound is in phase II study as single agent in patients with advanced BRCA1/2 mutated breast or ovarian cancer (NCT00664781), and in phase I study in combination with cytotoxic agents in patients with advanced solid tumor (NCT01009190).

\section{ABT-888 (Veliparib)}

ABT-888 is an oral PARP inhibitor. Preclinical studies in breast cancer, melanoma and glioma models demonstrated that ABT-888 potentates the chemotherapy effect of a number of agents including temozolomide, platinum, and irinotecan, as well as radiation [117]. Tan et al. reported the preliminary result of a phase I trial of ABT-888 in combination with cyclophosphamide in patients with advanced solid tumors [118]. ABT-888 50 mg twice daily can be safely combined with cyclophosphamide $750 \mathrm{mg} / \mathrm{m}^{2}$. ABT-888 does not alter the pharmacokinetics of cyclophosphamide. This study is still ongoing to determine the MTD of ABT-888 and cyclophosphamide combination.

A phase I study of ABT-888 in combination with metronomic cyclophosphamide revealed activity in BRCA mutated ovarian cancer and TNBC [119]. A phase II trial of ABT-888 $40 \mathrm{mg}$ twice daily on days 1 to 7 in combination with temozolomide $150 \mathrm{mg} / \mathrm{m}^{2}$, days 1-5 on a 28 days cycles for metastatic breast cancer was well tolerated [120]. However, activity was limited to BRCA mutation carriers. Of 8 patients with BRCA1/2 mutation, $37.5 \%$ RR and $62.5 \%$ DCR were observed. Medial PFS was 5.5 months in BRCA mutation carriers vs. 1.8 months in non-carriers. This study calls into question of "BRCAness" for at least this PARP inhibitor.
ABT-888 is currently being evaluated in many phase I/II studies in combination with chemotherapy or radiation in patients with advanced solid tumors.

\section{MK-4827}

MK-4827 is an orally bioavailable PARP inhibitor. This compound displays potent PARP-1 and PARP-2 inhibition, and inhibits proliferation of breast cancer cells with mutant BRCA-1 and BRCA-2 with $\mathrm{IC}_{50}$ in the range of 10-100 $\mathrm{nM}$ [121]. Sandhu et al reported phase I result of MK-4827 in 59 patients with advanced solid tumors in 2010 annual meeting of ASCO [122]. MTD was identified at $300 \mathrm{mg}$ daily with common toxicities in nausea/vomiting, fatigue and thrombocytopenia. Two out of six patients on $400 \mathrm{mg}$ daily experienced DLT with grade 4 thrombocytopenia was seen in 2 out of 6 patients received $400 \mathrm{mg}$ daily. Antitumor activity was observed in patients with BRCA-deficient cancers (32\% PR in 19 patients with ovarian cancer, and 50\% PR in 4 patients with breast cancer). Additionally, PR was seen in 1 patient with sporadic platinum-sensitive ovarian cancer. These findings have shown good tolerability and promising antitumor activity of MK-4827 in both BRCA-deficient and sporadic cancers. Phase I study in expanded cohorts with sporadic ovarian and prostate cancers is currently underway (NCT00749502). Phase IB dose escalation study of MK-4827 in combination with carboplatin, carboplatin/paclitaxel or carboplatin/doxil in patients with advanced solid tumors has also been activated (NCT01110603).

\section{CEP-9722}

Preclinical studies have shown CEP-9722 enhances cellular sensitivity toward temozolomide, irinotecan and radiation in various cancer types such as glioblastoma, colon cancer, neuroblastoma, and rhabdomyosarcoma [123]. CEP-9722 is currently undergoing phase I trial as single agent and in combination with temozolomide in advanced solid tumor (NCT00920595).

\section{E7016}

E7016 (previously known as GPI-21016) is an orally bioavailable PARP inhibitor. In murine leukemia model, E7016 enhances cisplatin-induced cytotoxicity and ameliorated cisplatin-induced neuropathy at the same time, suggesting a role to improve the therapeutic margin of certain cytotoxic agent [124]. Further study in human glioblastoma cell line and xenograft, E7016 enhances tumor radiosensitivity, and synergizes with combination treatment of temozolomide and radiation [125]. There is an ongoing phase I study with dose escalation of E7016 in combination with temozolomide in patients with advanced solid tumors and gliomas (NCT01127178). 


\section{Summary}

We reviewed preclinical data and clinical development of MDM2, ALK and PARP inhibitors. Cancer treatment is entering an exciting chapter in targeted therapies and personalized medicine due to the advance of molecular biology and medicinal chemistry. Most likely several compounds from this review will be approved for clinical use in the years to come. Many questions remain to be answered: (1) what are the long-term safety and toxicities of these inhibitors (2) how to use biomarkers to select patients who will benefit most from these inhibitors (3) how to combine these targeted therapies with cytotoxic agents or other treatment modality such as radiation modality in selected patient population?

More than 50 percent of human tumors contain a mutation or deletion of the p53 gene. Mutation of p53 can confer dominant-negative or gain-of-function effects [126]. Dominant-negative effects lead to suppression of wild-type p53 protein in heterozygous mutant cells and a p53 null phenotype; gain-of-function effects result in promotion of tumor development. There have been concerns on the exposure of MDM2 inhibitors to tumors with mutant $\mathrm{p} 53$, which potentially can have deleterious effects due to stabilization of mutant p53 [127].

Cautions need to be taken with long-term use of PARP inhibitors. PARP-1 serves important roles in other cellular function such as transcription regulation, initiation of a unique cell death pathway, restarting stalled replication forks, and modulation of cellular responses to ischemia, inflammation and necrosis [128]. Previous studies indicated that genetic ablation of PARP-1 in combination with p53 knockout increased cancer incidence in mice [129]. This raises concern that long-term PAPR-1 inhibition could potentially increase the risk of secondary malignancies.

\section{Author details}

${ }^{1}$ Division of Medical Oncology and Hematology, Loma Linda University Medical Center, Loma Linda, CA 92354, USA. ²Department of Internal Medicine, China Medical University Hospital, Taichung, Taiwan, China.

\section{Authors' contributions}

HRM and CTH designed the paper. YY, YML, CTH and HRM wrote the paper. All authors read and approved the final manuscript.

\section{Competing interests}

The authors declare that they have no competing interests.

Received: 27 January 2011 Accepted: 20 April 2011

Published: 20 April 2011

\section{References}

1. Fakharzadeh SS, Trusko SP, George DL: Tumorigenic potential associated with enhanced expression of a gene that is amplified in a mouse tumor cell line. EMBO J 1991, 10(6):1565-9.

2. Haupt $\mathrm{Y}$, et al: Mdm2 promotes the rapid degradation of $\mathrm{p} 53$. Nature 1997, 387(6630):296-9.
3. Bond $G L, H u W$, Levine AJ: MDM2 is a central node in the $p 53$ pathway: 12 years and counting. Curr Cancer Drug Targets 2005, 5(1):3-8.

4. Piette J, Neel H, Marechal V: Mdm2: keeping p53 under control. Oncogene 1997, 15(9):1001-10.

5. Momand J, et al: The MDM2 gene amplification database. Nucleic Acids Res 1998, 26(15):3453-9.

6. Montes de Oca Luna R, Wagner DS, Lozano G: Rescue of early embryonic lethality in mdm2-deficient mice by deletion of p53. Nature 1995, 378(6553):203-6.

7. de Rozieres $\mathrm{S}$, et al: The loss of $\mathrm{mdm} 2$ induces p53-mediated apoptosis. Oncogene 2000, 19(13):1691-7.

8. Steinman HA, et al: An alternative splice form of Mdm2 induces p53independent cell growth and tumorigenesis. J Biol Chem 2004, 279(6):4877-86.

9. Terzian T, et al: The inherent instability of mutant $p 53$ is alleviated by Mdm2 or p16INK4a loss. Genes Dev 2008, 22(10):1337-44.

10. Onel K, Cordon-Cardo C: MDM2 and prognosis. Mol Cancer Res 2004, 2(1):1-8

11. Heist RS, et al: MDM2 polymorphism, survival, and histology in earlystage non-small-cell lung cancer. J Clin Oncol 2007, 25(16):2243-7.

12. Wasylyk $C$, et al: p53 mediated death of cells overexpressing MDM2 by an inhibitor of MDM2 interaction with p53. Oncogene 1999, 18(11):1921-34.

13. Chene $P$, et al: A small synthetic peptide, which inhibits the p53-hdm2 interaction, stimulates the p53 pathway in tumour cell lines. $J$ Mol Biol 2000, 299(1):245-53.

14. Wang $\mathrm{H}$, et al: Anti-tumor efficacy of a novel antisense anti-MDM2 mixed-backbone oligonucleotide in human colon cancer models: p53dependent and p53-independent mechanisms. Mol Med 2002, 8(4):185-99.

15. Xue $W$, et al: Senescence and tumour clearance is triggered by $p 53$ restoration in murine liver carcinomas. Nature 2007, 445(7128):656-60.

16. Ventura $A$, et al: Restoration of $p 53$ function leads to tumour regression in vivo. Nature 2007, 445(7128):661-5.

17. Martins CP, Brown-Swigart L, Evan Gl: Modeling the therapeutic efficacy of p53 restoration in tumors. Cell 2006, 127(7):1323-34

18. Kussie PH, et al: Structure of the MDM2 oncoprotein bound to the p53 tumor suppressor transactivation domain. Science 1996, 274(5289):948-53.

19. Patel S, Player MR: Small-molecule inhibitors of the p53-HDM2 interaction for the treatment of cancer. Expert Opin Investig Drugs 2008, 17(12):1865-82.

20. Cheok CF, et al: Translating p53 into the clinic. Nat Rev Clin Oncol advance online publication; 2010

21. Klein C, Vassilev LT: Targeting the p53-MDM2 interaction to treat cancer Br J Cancer 2004, 91(8):1415-9.

22. Vassilev LT: Small-molecule antagonists of p53-MDM2 binding: research tools and potential therapeutics. Cell Cycle 2004, 3(4):419-21.

23. Vassilev $L T$, et al: In vivo activation of the $p 53$ pathway by smallmolecule antagonists of MDM2. Science 2004, 303(5659):844-8.

24. Tovar C, et al: Small-molecule MDM2 antagonists reveal aberrant p53 signaling in cancer: implications for therapy. Proc Natl Acad Sci USA 2006, 103(6):1888-93.

25. Shangary S, S Wang: Small-molecule inhibitors of the MDM2-p53 proteinprotein interaction to reactivate p53 function: a novel approach for cancer therapy. Annu Rev Pharmacol Toxicol 2009, 49:223-41.

26. Van Maerken T, et al: Antitumor activity of the selective MDM2 antagonist nutlin-3 against chemoresistant neuroblastoma with wildtype p53. J Natl Cancer Inst 2009, 101(22):1562-74.

27. Tabe $Y$, et al: MDM2 antagonist nutlin-3 displays antiproliferative and proapoptotic activity in mantle cell lymphoma. Clin Cancer Res 2009, 15(3):933-42.

28. Hasegawa $\mathrm{H}$, et al: Activation of $\mathrm{p} 53$ by Nutlin-3a, an antagonist of MDM2, induces apoptosis and cellular senescence in adult T-cell leukemia cells. Leukemia 2009, 23(11):2090-2101.

29. Kojima $K$, et al: MDM2 antagonists induce p53-dependent apoptosis in AML: implications for leukemia therapy. Blood 2005, 106(9):3150-9.

30. Lau LM, et al: HDM2 antagonist Nutlin-3 disrupts p73-HDM2 binding and enhances p73 function. Oncogene 2008, 27(7):997-1003.

31. Jackson MW, Berberich SJ: MdmX protects $\mathrm{p} 53$ from Mdm2-mediated degradation. Mol Cell Biol 2000, 20(3):1001-7. 
32. Wade $\mathrm{M}$, et al: Hdmx modulates the outcome of $\mathrm{p} 53$ activation in human tumor cells. J Biol Chem 2006, 281(44):33036-44.

33. Wang $H$, et al: A Small-Molecule Inhibitor of MDMX Activates p53 and Induces Apoptosis. Molecular Cancer Therapeutics 2010, 10(1):69-79.

34. Arts J, et al: JNJ-26854165 - a novel HDM2 antagonist in clinical development showing broad-spectrum preclinical antitumour activity against solid malignancies. Proc Am Assoc Cancer Res 2008, 49, Abstract 1592.

35. Stuhmer T, et al: A first-in-class HDM2-inhibitor (JNJ-26854165) in phase I development shows potent activity against multiple myeloma (MM) cells in vitro and ex vivo. J Clin Oncol (Meeting Abstracts) 2008 26(15_suppl):14694.

36. Kojima K, et al: The novel tryptamine derivative JNJ-26854165 induces wild-type p53- and E2F1-mediated apoptosis in acute myeloid and lymphoid leukemias. Mol Cancer Ther 2010, 9(9):2545-57.

37. Tabernero J, et al: Phase I pharmacokinetic (PK) and pharmacodynamic (PD) study of HDM-2 antagonist JNJ-26854165 in patients with advanced refractory solid tumors. J Clin Oncol (Meeting Abstracts) 2009, 27(15S):3514.

38. Yang $\mathrm{H}$, et al: Macrophage inhibitory cytokine-1: a novel biomarker for p53 pathway activation. Mol Cancer Ther 2003, 2(10):1023-9.

39. Wasik MA, et al: Anaplastic lymphoma kinase (ALK)-induced malignancies: novel mechanisms of cell transformation and potential therapeutic approaches. Semin Oncol 2009, 36(2 Suppl 1):S27-35.

40. Chiarle $R$, et al: The anaplastic lymphoma kinase in the pathogenesis of cancer. Nat Rev Cancer 2008, 8(1):11-23.

41. Morris SW, et al: Fusion of a kinase gene, ALK, to a nucleolar protein gene, NPM, in non-Hodgkin's lymphoma. Science 1994, 263(5151):1281-4.

42. Amin HM, Lai R: Pathobiology of ALK+ anaplastic large-cell lymphoma. Blood 2007, 110(7):2259-67.

43. Chen $Y$, et al: Oncogenic mutations of ALK kinase in neuroblastoma. Nature 2008, 455(7215):971-974

44. Sharma SV, Settleman J: Oncogene addiction: setting the stage for molecularly targeted cancer therapy. Genes Dev 2007, 21(24):3214-31.

45. Piva $R$, et al: Ablation of oncogenic ALK is a viable therapeutic approach for anaplastic large-cell lymphomas. Blood 2006, 107(2):689-97.

46. Houtman $\mathrm{SH}$, et al: Echinoderm microtubule-associated protein like protein 4 , a member of the echinoderm microtubule-associated protein family, stabilizes microtubules. Neuroscience 2007, 144(4):1373-82.

47. Choi $Y L$, et al: Identification of novel isoforms of the EML4-ALK transforming gene in non-small cell lung cancer. Cancer Res 2008 68(13):4971-6.

48. Soda $M$, et al: Identification of the transforming EML4-ALK fusion gene in non-small-cell lung cancer. Nature 2007, 448(7153):561-6.

49. Takeuchi $K$, et al: Multiplex reverse transcription-PCR screening for EML4ALK fusion transcripts. Clin Cancer Res 2008, 14(20):6618-24.

50. Takeuchi $\mathrm{K}$, et al: KIF5B-ALK, a novel fusion oncokinase identified by an immunohistochemistry-based diagnostic system for ALK-positive lung cancer. Clin Cancer Res 2009, 15(9):3143-9.

51. Wong DW, et al: The EML4-ALK fusion gene is involved in various histologic types of lung cancers from nonsmokers with wild-type EGFR and KRAS. Cancer 2009, 115(8):1723-33.

52. Perner $S$, et al: EML4-ALK fusion lung cancer: a rare acquired event. Neoplasia 2008, 10(3):298-302.

53. Inamura $K$, et al: EML4-ALK fusion is linked to histological characteristics in a subset of lung cancers. J Thorac Oncol 2008, 3(1):13-7.

54. Shinmura $K$, et al: EML4-ALK fusion transcripts, but no NPM-, TPM3-, CLTC-, ATIC-, or TFG-ALK fusion transcripts, in non-small cell lung carcinomas. Lung Cancer 2008, 61(2):163-9.

55. Shaw AT, et al: Clinical features and outcome of patients with non-smallcell lung cancer who harbor EML4-ALK. J Clin Oncol 2009, 27(26):4247-53.

56. Fukuyoshi $Y$, et al: EML4-ALK fusion transcript is not found in gastrointestinal and breast cancers. Br J Cancer 2008, 98(9):1536-9.

57. Shaw AT, et al: Prognostic versus predictive value of EML4-ALK translocation in metastatic non-small cell lung cancer. J Clin Oncol (Meeting Abstracts) 2010, 28(15_suppl):7606.

58. Li R, Morris SW: Development of anaplastic lymphoma kinase (ALK) small-molecule inhibitors for cancer therapy. Med Res Rev 2008, 28(3):372-412.
59. Gunby RH, et al: Structural insights into the ATP binding pocket of the anaplastic lymphoma kinase by site-directed mutagenesis, inhibitor binding analysis, and homology modeling. J Med Chem 2006, 49(19):5759-68.

60. Zou HY, et al: An Orally Available Small-Molecule Inhibitor of c-Met, PF2341066, Exhibits Cytoreductive Antitumor Efficacy through Antiproliferative and Antiangiogenic Mechanisms. Cancer Research 2007, 67(9):4408-4417.

61. Christensen JG, et al: Cytoreductive antitumor activity of PF-2341066, a novel inhibitor of anaplastic lymphoma kinase and c-Met, in experimental models of anaplastic large-cell lymphoma. Mol Cancer Ther 2007, 6(12 Pt 1):3314-22

62. McDermott $U$, et al: Genomic alterations of anaplastic lymphoma kinase may sensitize tumors to anaplastic lymphoma kinase inhibitors. Cancer Res 2008, 68(9):3389-95.

63. Shakespeare WC, et al: Discovery of potent and selective orally active inhibitors of anaplastic lymphoma kinase (ALK). Proc Am Assoc Cancer Res 2009, 50, Abstract 3738.

64. Zhang S, et al: AP26113, a potent ALK inhibitor, overcomes mutations in EML4-ALK that confer resistance to PF-02341066 (PF1066). Proc Am Assoc Cancer Res 2010, 51, Abstract LB-298.

65. Rivera VM, et al: Efficacy and pharmacodynamic analysis of AP26113, a potent and selective orally active inhibitor of Anaplastic Lymphoma Kinase (ALK). Proc Am Assoc Cancer Res 2010, 51, Abstract 3623.

66. Kwak EL, et al: Clinical activity observed in a phase I dose escalation trial of an oral c-met and ALK inhibitor, PF-02341066. J Clin Oncol (Meeting Abstracts) 2009, 27(15S):3509.

67. Bang Y, et al: Clinical activity of the oral ALK inhibitor PF-02341066 in ALK-positive patients with non-small cell lung cancer (NSCLC). J Clin Oncol (Meeting Abstracts) 2010, 28(18_suppl):3.

68. Kwak EL, et al: Anaplastic lymphoma kinase inhibition in non-small-cell lung cancer. N Engl J Med 2010, 363(18):1693-703.

69. Rouleau M, et al: PARP inhibition: PARP1 and beyond. Nat Rev Cancer 2010, 10(4):293-301.

70. Durkacz BW, et al: (ADP-ribose)n participates in DNA excision repair. Nature 1980, 283(5747):593-596.

71. Burkle A: Poly(ADP-ribose). The most elaborate metabolite of NAD+. FEBS J 2005, 272(18):4576-89.

72. Huber A, et al: PARP-1, PARP-2 and ATM in the DNA damage response: functional synergy in mouse development. DNA Repair (Amst) 2004, 3(89):1103-8.

73. Shieh WM, et al: Poly(ADP-ribose) polymerase null mouse cells synthesize ADP-ribose polymers. J Biol Chem 1998, 273(46):30069-72.

74. Yelamos J, Schreiber V, Dantzer F: Toward specific functions of poly(ADPribose) polymerase-2. Trends Mol Med 2008, 14(4):169-78.

75. Ratnam K, Low JA: Current development of clinical inhibitors of poly (ADP-ribose) polymerase in oncology. Clin Cancer Res 2007, 13(5):1383-8.

76. Puhalla S: PARP inhibitors: what we know and what we have yet to know. Oncology (Williston Park) 2010, 24(1):62, 65-6.

77. Comen EA, Robson M: Inhibition of poly(ADP)-ribose polymerase as a therapeutic strategy for breast cancer. Oncology (Williston Park) 2010, 24(1):55-62.

78. Carden CP, Yap TA, Kaye SB: PARP inhibition: targeting the Achilles' heel of DNA repair to treat germline and sporadic ovarian cancers. Curr Opin Oncol 2010, 22(5):473-80.

79. Plummer ER, Calvert H: Targeting poly(ADP-ribose) polymerase: a twoarmed strategy for cancer therapy. Clin Cancer Res 2007, 13(21):6252-6.

80. Farmer $\mathrm{H}$, et al: Targeting the DNA repair defect in BRCA mutant cells as a therapeutic strategy. Nature 2005, 434(7035):917-21.

81. Bryant HE, et al: Specific killing of BRCA2-deficient tumours with inhibitors of poly(ADP-ribose) polymerase. Nature 2005, 434(7035):913-7.

82. Turner N, Tutt A, Ashworth A: Hallmarks of 'BRCAness' in sporadic cancers. Nat Rev Cancer 2004, 4(10):814-9.

83. McCabe $N$, et al: Deficiency in the repair of DNA damage by homologous recombination and sensitivity to poly(ADP-ribose) polymerase inhibition. Cancer Res 2006, 66(16):8109-15.

84. Mendes-Pereira AM, et al: Synthetic lethal targeting of PTEN mutant cells with PARP inhibitors. EMBO Mol Med 2009, 1(6-7):315-22. 
85. Konstantinopoulos PA, et al: Gene expression profile of BRCAness that correlates with responsiveness to chemotherapy and with outcome in patients with epithelial ovarian cancer. J Clin Oncol 2010, 28(22):3555-61.

86. Hastak K, Ford E, Alli JM: Synergistic chemosensitivity of triple-negative breast cancer cell lines to poly(ADP-Ribose) polymerase inhibition, gemcitabine, and cisplatin. Cancer Res 2010, 70(20):7970-80.

87. Ishida J, et al: Discovery of potent and selective PARP-1 and PARP-2 inhibitors: SBDD analysis via a combination of X-ray structural study and homology modeling. Bioorg Med Chem 2006, 14(5):1378-90.

88. Yoo AR, et al: Effects of a newly developed tricyclic PARP-1 inhibitor, on ischemic stroke. Drug Dev Res 2010, 71(4):253-260.

89. Pellicciari $R$, et al: On the way to selective PARP-2 inhibitors. Design, synthesis, and preliminary evaluation of a series of isoquinolinone derivatives. ChemMedChem 2008, 3(6):914-23.

90. Eliasson MJ, et al: Poly(ADP-ribose) polymerase gene disruption renders mice resistant to cerebral ischemia. Nat Med 1997, 3(10):1089-95.

91. Graziani G, Battaini F, Zhang J: PARP-1 inhibition to treat cancer, ischemia, inflammation. Pharmacol Res 2005, 52(1):1-4.

92. Szabo C: Cardioprotective effects of poly(ADP-ribose) polymerase inhibition. Pharmacol Res 2005, 52(1):34-43.

93. Radovits T, et al: Single dose treatment with PARP-inhibitor INO-1001 improves aging-associated cardiac and vascular dysfunction. Exp Gerontol 2007, 42(7):676-85

94. Matsuura S, et al: MP-124, a novel poly(adp-ribose)polymerase (PARP) inhibitor, ameliorates the ischemic damage in non-human primate model (2009 International Stroke Conference). Stroke 2009, 40(4), Abstract P251.

95. McCabe N, et al: Targeting Tankyrase 1 as a therapeutic strategy for BRCA-associated cancer. Oncogene 2009, 28(11):1465-1470.

96. Huang S-MA, et al: Tankyrase inhibition stabilizes axin and antagonizes Wnt signalling. Nature 2009, 461(7264):614-620.

97. Bedikian AY, et al: A phase IB trial of intravenous INO-1001 plus oral temozolomide in subjects with unresectable stage-III or IV melanoma. Cancer Invest 2009, 27(7):756-63.

98. Inotek Pharmaceuticals Pipeline. [http://www.inotekcorp.com/content/ pipeline overview.asp], [cited 2011 March 18]

99. Annunziata CM, O'Shaughnessy J: Poly (ADP-ribose) polymerase as a novel therapeutic target in cancer. Clin Cancer Res 2010, 16(18):4517-26.

100. Ferraris DV: Evolution of poly(ADP-ribose) polymerase-1 (PARP-1) inhibitors. From concept to clinic. J Med Chem 2010, 53(12):4561-84.

101. Kopetz S, et al: First in human phase I study of BSI-201, a small molecule inhibitor of poly ADP-ribose polymerase (PARP) in subjects with advanced solid tumors. J Clin Oncol (Meeting Abstracts) 2008, 26(15_suppl):3577.

102. Mahany JJ, et al: A phase IB study evaluating BSI-201 in combination with chemotherapy in subjects with advanced solid tumors. J Clin Oncol (Meeting Abstracts) 2008, 26(15 suppl):3579.

103. OShaughnessy JOC, Pippen J, et al: Efficacy of BSI-201, a poly (ADP-ribose) ploymerase-1(PARP1) inhibitor, in combination with gemcitabine/ carboplatin $(\mathrm{G} / \mathrm{C})$ in patients with metastatic triple-negative breast cancer (TNBC): Results of a randomized phase II trial. J Clin Oncol (Meeting Abstracts) 2009, 27(15S):3.

104. Audeh MW, et al: Phase II trial of the oral PARP inhibitor olaparib (AZD2281) in BRCA-deficient advanced ovarian cancer. J Clin Oncol (Meeting Abstracts) 2009, 27(15S):5500

105. Fong PC, et al: AZD2281 (KU-0059436), a PARP (poly ADP-ribose polymerase) inhibitor with single agent anticancer activity in patients with BRCA deficient ovarian cancer: Results from a phase I study. I Clin Oncol (Meeting Abstracts) 2008, 26(15_suppl):5510.

106. Fong PC, et al: Inhibition of poly(ADP-ribose) polymerase in tumors from BRCA mutation carriers. N Engl J Med 2009, 361(2):123-34.

107. Tutt $A$, et al: Phase II trial of the oral PARP inhibitor olaparib in BRCAdeficient advanced breast cancer. J Clin Oncol (Meeting Abstracts) 2009, 27(18S):CRA501.

108. Fong PC, et al: Poly(ADP)-Ribose Polymerase Inhibition: Frequent Durable Responses in BRCA Carrier Ovarian Cancer Correlating With PlatinumFree Interval. J Clin Oncol 2010, 28(15):2512-2519.

109. Audeh MW, et al: Oral poly(ADP-ribose) polymerase inhibitor olaparib in patients with BRCA1 or BRCA2 mutations and recurrent ovarian cancer: a proof-of-concept trial. The Lancet 2010, 376(9737):245-251.
110. Tutt $A$, et al: Oral poly(ADP-ribose) polymerase inhibitor olaparib in patients with BRCA1 or BRCA2 mutations and advanced breast cancer: a proof-of-concept trial. The Lancet 2010, 376(9737):235-244

111. Gelmon KA, et al: Can we define tumors that will respond to PARP inhibitors? A phase II correlative study of olaparib in advanced serous ovarian cancer and triple-negative breast cancer. J Clin Oncol (Meeting Abstracts) 2010, 28(15_suppl):3002.

112. Tan DS, et al: "BRCAness" syndrome in ovarian cancer: a case-control study describing the clinical features and outcome of patients with epithelial ovarian cancer associated with BRCA1 and BRCA2 mutations. J Clin Oncol 2008, 26(34):5530-6.

113. Giaccone $G$, et al: A phase I combination study of olaparib (AZD2281; KU-0059436) and cisplatin (C) plus gemcitabine (G) in adults with solid tumors. J Clin Oncol (Meeting Abstracts) 2010, 28(15_suppl):3027.

114. Dent RA, et al: Safety and efficacy of the oral PARP inhibitor olaparib (AZD2281) in combination with paclitaxel for the first- or second-line treatment of patients with metastatic triple-negative breast cancer: Results from the safety cohort of a phase I/II multicenter trial. J Clin Oncol (Meeting Abstracts) 2010, 28(15_suppl):1018.

115. Plummer $\mathrm{R}$, et al: Phase I study of the poly(ADP-ribose) polymerase inhibitor, AG014699, in combination with temozolomide in patients with advanced solid tumors. Clin Cancer Res 2008, 14(23):7917-23.

116. Plummer $R$, et al: First and final report of a phase II study of the poly (ADP-ribose) polymerase (PARP) inhibitor, AG014699, in combination with temozolomide (TMZ) in patients with metastatic malignant melanoma (MM). J Clin Oncol (Meeting Abstracts) 2006, 24(18_suppl):8013.

117. Kummar $S$, et al: Phase 0 clinical trial of the poly (ADP-ribose) polymerase inhibitor ABT-888 in patients with advanced malignancies. J Clin Oncol 2009, 27(16):2705-11

118. Tan AR, et al: Preliminary results of a phase I trial of ABT-888, a poly (ADP-ribose) polymerase (PARP) inhibitor, in combination with cyclophosphamide. J Clin Oncol (Meeting Abstracts) 2010, 28(15_suppl):3000

119. Kummar S, et al: A phase I study of ABT-888 (A) in combination with metronomic cyclophosphamide (C) in adults with refractory solid tumors and lymphomas. J Clin Oncol (Meeting Abstracts) 2010, 28(15_suppl):2605.

120. Isakoff SJ, et al: A phase II trial of the PARP inhibitor veliparib (ABT888) and temozolomide for metastatic breast cancer. J Clin Oncol (Meeting Abstracts) 2010, 28(15 suppl):1019.

121. Jones $\mathrm{P}$, et al: Discovery of 2-\{4-[(3S)-Piperidin-3-yl]phenyl\}-2H-indazole-7carboxamide (MK-4827): A Novel Oral Poly(ADP-ribose)polymerase (PARP) Inhibitor Efficacious in BRCA-1 and -2 Mutant Tumors. Journal of Medicinal Chemistry 2009, 52(22):7170-7185.

122. Sandhu SK, et al: First-in-human trial of a poly(ADP-ribose) polymerase (PARP) inhibitor MK-4827 in advanced cancer patients (pts) with antitumor activity in BRCA-deficient and sporadic ovarian cancers. J Clin Oncol (Meeting Abstracts) 2010, 28(15_suppl):3001.

123. Miknyoczki $\mathrm{S}$, et al: The selective poly(ADP-ribose) polymerase-1(2) inhibitor, CEP-8983, increases the sensitivity of chemoresistant tumor cells to temozolomide and irinotecan but does not potentiate myelotoxicity. Mol Cancer Ther 2007, 6(8):2290-2302.

124. Lapidus RG, et al: PARP inhibitors enhance the effect of cisplatin against tumors and ameliorate cisplatin-induced neuropathy. Proc Am Assoc Cancer Res 2006, 47, Abstract 506.

125. Russo $A L$, et al: In vitro and in vivo radiosensitization of glioblastoma cells by the poly (ADP-ribose) polymerase inhibitor E7016. Clin Cancer Res 2009, 15(2):607-12

126. Sigal A, Rotter V: Oncogenic mutations of the p53 tumor suppressor: the demons of the guardian of the genome. Cancer Res 2000, 60(24):6788-93.

127. Marine JC, Lozano G: Mdm2-mediated ubiquitylation: p53 and beyond. Cell Death Differ 2010, 17(1):93-102.

128. Patel A, Kaufmann SH: Development of PARP inhibitors: an unfinished story. Oncology (Williston Park) 2010, 24(1):66-68.

129. Tong WM, et al: Null mutation of DNA strand break-binding molecule poly(ADP-ribose) polymerase causes medulloblastomas in p53(-/-) mice. Am J Pathol 2003, 162(1):343-52.

130. Grasberger BL, et al: Discovery and cocrystal structure of benzodiazepinedione HDM2 antagonists that activate p53 in cells. J Med Chem 2005, 48(4):909-12. 
131. Koblish HK, et al: Benzodiazepinedione inhibitors of the Hdm2:p53 complex suppress human tumor cell proliferation in vitro and sensitize tumors to doxorubicin in vivo. Mol Cancer Ther 2006, 5(1):160-9.

132. Ding K, et al: Structure-Based Design of Spiro-oxindoles as Potent, Specific Small-Molecule Inhibitors of the MDM2â^"p53 Interaction. Journal of Medicinal Chemistry 2006, 49(12):3432-3435.

133. Shangary $S$, et al: Temporal activation of $\mathrm{p} 53$ by a specific MDM2 inhibitor is selectively toxic to tumors and leads to complete tumor growth inhibition. Proc Natl Acad Sci USA 2008, 105(10):3933-3938.

134. Mohammad R, et al: An MDM2 antagonist (MI-319) restores p53 functions and increases the life span of orally treated follicular lymphoma bearing animals. Mol Cancer 2009, 8(1):115.

135. Rothweiler $U$, et al: Isoquinolin-1-one Inhibitors of the MDM2-p53 Interaction. ChemMedChem 2008, 3(7):1118-1128.

136. Nieves-Neira W, et al: DNA protein cross-links produced by NSC 652287 , a novel thiophene derivative active against human renal cancer cells. $\mathrm{Mol}$ Pharmacol 1999, 56(3):478-84.

137. Issaeva N, et al: Small molecule RITA binds to p53, blocks p53-HDM-2 interaction and activates p53 function in tumors. Nat Med 2004, 10(12):1321-8.

138. Yang $Y$, et al: Small molecule inhibitors of HDM2 ubiquitin ligase activity stabilize and activate p53 in cells. Cancer Cell 2005, 7(6):547-559.

139. Wilson JM, et al: Synthesis of 5-deazaflavin derivatives and their activation of p53 in cells. Bioorg Med Chem 2007, 15(1):77-86.

140. CEP-28122. 2010 [http://www.cephalon.com]

141. Ott GR, et al: Discovery of a potent Inhibitor of anaplastic lymphoma kinase with in vivo antitumor activity. ACS Med Chem Lett 2010, 1(9):493-498.

142. Lovly CM, et al: Preclinical development of a selective, potent small molecule ALK inhibitor. Proc Am Assoc Cancer Res 2010, 51, Abstract 1788.

143. Kruczynski $A$, et al: Antitumor activity of pyridoisoquinoline derivatives F91873 and F91874, novel multikinase inhibitors with activity against the anaplastic lymphoma kinase. Anti-Cancer Drugs 2009, 20(5):364-372.

144. Fancelli $D$, et al: 1,4,5,6-Tetrahydropyrrolo[3,4-c]pyrazoles:??Identification of a Potent Aurora Kinase Inhibitor with a Favorable Antitumor Kinase Inhibition Profile. Journal of Medicinal Chemistry 2006, 49(24):7247-7251.

145. Bossi RT, et al: Crystal Structures of Anaplastic Lymphoma Kinase in Complex with ATP Competitive Inhibitors. Biochemistry 2010, 49(32):6813-6825.

146. Wan W, et al: Anaplastic lymphoma kinase activity is essential for the proliferation and survival of anaplastic large-cell lymphoma cells. Blood 2006, 107(4):1617-1623.

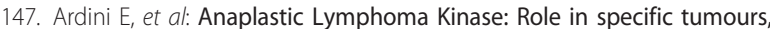
and development of small molecule inhibitors for cancer therapy. Cancer Letters 2010, 299(2):81-94.

148. Sabbatini $P$, et al: GSK1838705A inhibits the insulin-like growth factor-1 receptor and anaplastic lymphoma kinase and shows antitumor activity in experimental models of human cancers. Mol Cancer Ther 2009, 8(10):2811-2820

149. Galkin AV, et al: Identification of NVP-TAE684, a potent, selective, and efficacious inhibitor of NPM-ALK. Proc Natl Acad Sci USA 2007, 104(1):270-275.

150. Chen Z, et al: Inhibition of ALK, PI3K/MEK, and HSP9O in Murine Lung Adenocarcinoma Induced by EML4-ALK Fusion Oncogene. Cancer Research 2010

151. Brock WA, et al: Radiosensitization of human and rodent cell lines by INO-1001, a novel inhibitor of poly(ADP-ribose) polymerase. Cancer Lett 2004, 205(2):155-60.

152. Cheng $C L$, et al: Poly(ADP-ribose) polymerase-1 inhibition reverses temozolomide resistance in a DNA mismatch repair-deficient malignant glioma xenograft. Mol Cancer Ther 2005, 4(9):1364-8.

153. MP-124. [http://www.mt-pharma-america.com/development.php], [cited 2010 December 16]

154. Wang B, et al: Novel PARP inhibitors with potent antitumor activity as single-agent and combination therapies. Mol Cancer Ther 2009, 8(Supplement 1), Abstract 121.

155. Plummer R: Perspective on the pipeline of drugs being developed with modulation of DNA damage as a target. Clin Cancer Res 2010, 16(18):4527-31.

156. Montagnoli A, et al: NMS-P118, a Parp-1 selective inhibitor with efficacy in DNA repair deficient tumor models in 22nd EORTC-NCI-AACR
Symposium on Molecular Targets and Cancer Therapeutics. Berlin, Germany 2010

doi:10.1186/1756-8722-4-16

Cite this article as: Yuan et al:: Novel targeted therapeutics: inhibitors of MDM2, ALK and PARP. Journal of Hematology \& Oncology 2011 4:16.

\section{Submit your next manuscript to BioMed Central and take full advantage of:}

- Convenient online submission

- Thorough peer review

- No space constraints or color figure charges

- Immediate publication on acceptance

- Inclusion in PubMed, CAS, Scopus and Google Scholar

- Research which is freely available for redistribution

Submit your manuscript at www.biomedcentral.com/submit
C Biomed Central 